\title{
Crioconservación de los recursos genéticos del cuy (Cavia porcellus): producción y congelación de embriones
}

Anne Grégoire, Thierry Joly, Ethel Huamán Fuertes, Rosa María Silva Arce y Silvia León Trinidad

\section{(2) OpenEdition}

Journals

Edición electrónica

URL: http://journals.openedition.org/bifea/2164

DOI: 10.4000/bifea.2164

ISSN: 2076-5827

Editor

Institut Français d'Études Andines

Edición impresa

Fecha de publicación: 1 abril 2010

Paginación: 185-188

ISSN: 0303-7495

Referencia electrónica

Anne Grégoire, Thierry Joly, Ethel Huamán Fuertes, Rosa María Silva Arce y Silvia León Trinidad, "Crioconservación de los recursos genéticos del cuy (Cavia porcellus): producción y congelación de embriones », Bulletin de l'Institut français d'études andines [En línea], 39 (1) | 2010, Publicado el 01 octubre 2010, consultado el 07 noviembre 2020. URL : http://journals.openedition.org/bifea/2164 DOI : https://doi.org/10.4000/bifea.2164

\section{c) (i) $९$}

Les contenus du Bulletin de l'Institut français d'études andines sont mis à disposition selon les termes de la licence Creative Commons Attribution - Pas d'Utilisation Commerciale - Pas de Modification 4.0 International. 


\section{Crioconservación de los recursos genéticos del cuy (Cavia porcellus): producción y congelación de embriones}

\section{Anne Grégoire*}

Thierry Joly"*

Ethel Huamán Fuertes**

Rosa María Silva Arce ${ }^{* *}$

Silvia León Trinidad***

El cuy (Cavia porcellus) es un animal emblemático de la diversidad genética de los animales domésticos de los Andes. Como tal, la conservación de la biodiversidad intraespecífica del cuy es primordial, tanto por ser una fuente de proteínas importante para los pobladores andinos como para conservar la herencia simbólica

del cuy, las prácticas culturales relacionadas con su crianza, como animal de consumo y en medicina tradicional. Por otro lado, los programas de selección llevados a cabo desde los años 1970 por el Instituto Nacional de Investigación Agraria del Perú dieron lugar a una nueva diversidad genética orientada hacia la

" IFEA, casilla 18-1217, Lima 18, Perú. UPSP École Nationale Vétérinaire de Lyon/ISARA-Lyon : Unite de recherche CRYOBIO. E-mail: anne.gregoire@gmail.com

** UPSP École Nationale Vétérinaire de Lyon/ISARA-Lyon : Unité de recherche CRYOBIO. E-mail: tjoly@isara.fr

*** Universidad Nacional Agraria La Molina: Centro de investigación y Enseñanza en Transferencia de Embriones-ClETE (Convenio Ministerio de Agricultura-Universidad Nacional Agraria La Molina). E-mails: ethelhf@gmail.com; rosamariasilva.arce@gmail.com; sleont@gmail.com 
formación de animales más productivos. Más aún el uso del cuy como un animal de laboratorio ha sido un valioso aporte andino para la investigación biomédica, humanos. El mayor éxito para conservar una especie es a través de las formas in situ y ex situ complementarias. El objetivo de nuestro proyecto de investigación es la elaboración de protocolos de producción y de congelación de embriones que permitan lograr una conservación ex situ de los recursos genéticos de esta especie, vía el recurso hembra. Las etapas necesarias a la concretización de este proyecto son el control de la producción de embriones, gracias a tratamientos hormonales de sincronización de los ciclos estrales y de superovulación de las hembras, y la crioconservación de los embriones obtenidos. Los protocolos eficaces para el control del ciclo estral del cuy (Cavia porcellus) son escasos. La sincronización de celos de Cavia porcellus es comúnmente obtenida en laboratorio usando un implante subcutáneo de progesterona similar al que se usa en contracepción humana (tubo de silicona de $1 \mathrm{~cm}$ de largo) durante 4 semanas. La hembra entra en celos 5-6 días luego de remover el implante (Ueda et al. 1988). Sin embargo el uso de este método es costoso y complicado de implementar fuera de las condiciones de asepsia de un laboratorio (el implante se coloca bajo anestesia general realizando un corte en la piel); además plantea problemas de bienestar animal. En nuestro caso la producción de embriones debe realizarse en condiciones de crianza en granja.

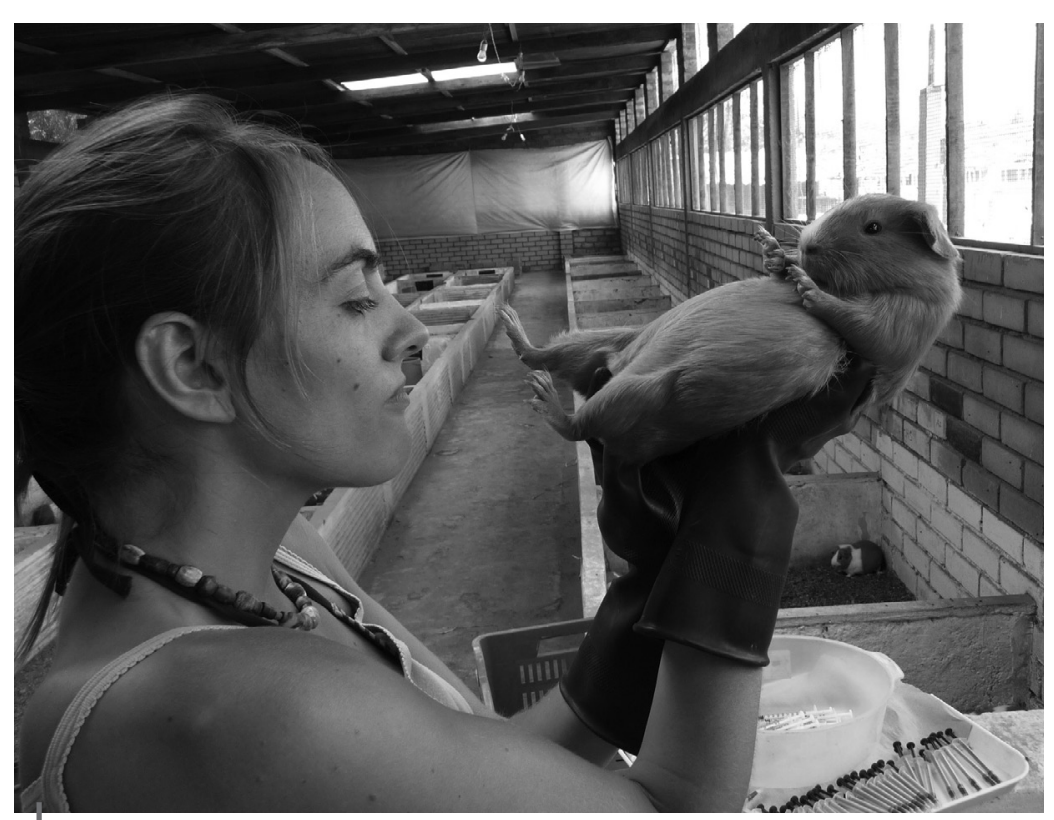

Figura 1 - Revisión diaria de aparición de celos en las hembras Foto: Thierry Joly

La primera etapa para la producción de embriones es la sincronización de los celos de las hembras. Para tal efecto se ha utilizado un análogo de progesterona de administración oral, el altrenogest, producto usado comúnmente en la sincronización de celo de cerdas y yeguas. En un ciclo natural, la fase lútea corresponde a la presencia de un cuerpo lúteo activo en el ovario, el cual secreta progesterona y bloquea una nueva ovulación. Cuando el cuerpo lúteo regresiona naturalmente, la secreción de progesterona cae y el retrocontrol negativo que ejerce sobre el hipotálamo desaparece. Entonces se estimula la secreción de FSH y LH por la hipófisis, lo que provoca el desarrollo de una nueva onda folicular y la ovulación. Al mantener alto el nivel de progesterona en el organismo de las hembras, se bloquean las nuevas ovulaciones consecutivas de la regresión de los cuerpos luteos, con el fin de obtener el inicio de un nuevo ciclo al retirar el tratamiento. Cavia porcellus presenta una longitud de ciclo de 16 días en promedio (con 12-13 días de fase lútea). Por ello se decidió aplicar la hormona por 20 días consecutivos para sincronizar todos los animales. Todas las hembras presentaron síntomas de celos a los 4-5 días después del retiro del tratamiento. Se comprobó la aparición de celos por observación de la apertura de la membrana vaginal así como el comportamiento de las hembras en presencia de un macho, al aceptar la monta $y$, entre hembras, al presentar agresividad para acceder al macho. Los primeros resultados muestran que la simulación de una fase lútea gracias a la aplicación diaria de progesteron oral permite sincronizar los celos de las hembras, en cualquier momento del ciclo estral. Este método presenta la ventaja de poder aplicarse en condiciones de granja, siempre y cuando los animales estén acostumbrados al manejo diario de quienes los manipulan, ya que el cuy es un animal muy sensible al estrés y neófobo. El estrés provocado por una manipulación diaria inadecuada o por personas desconocidas puede estresar el animal de manera significativa (perdida de pelos, de peso) y hasta ser letal. Otra limitante de este método es la dificultad que representa aplicar un tratamiento diario a hora fija durante 20 días en otras condicione que no sean experimentales.

Con el fin de limitar tanto el estrés de los animales como la obligación de los trabajadores, se h elaborado un nuevo tratamiento menos tedioso el cual se basa en el uso de prostaglandinas. En un ciclo natural y en ausencia de la implantación de un embrión en el útero, la mucosa uterin secreta prostaglandinas PGF2 $\alpha$, que provoca I

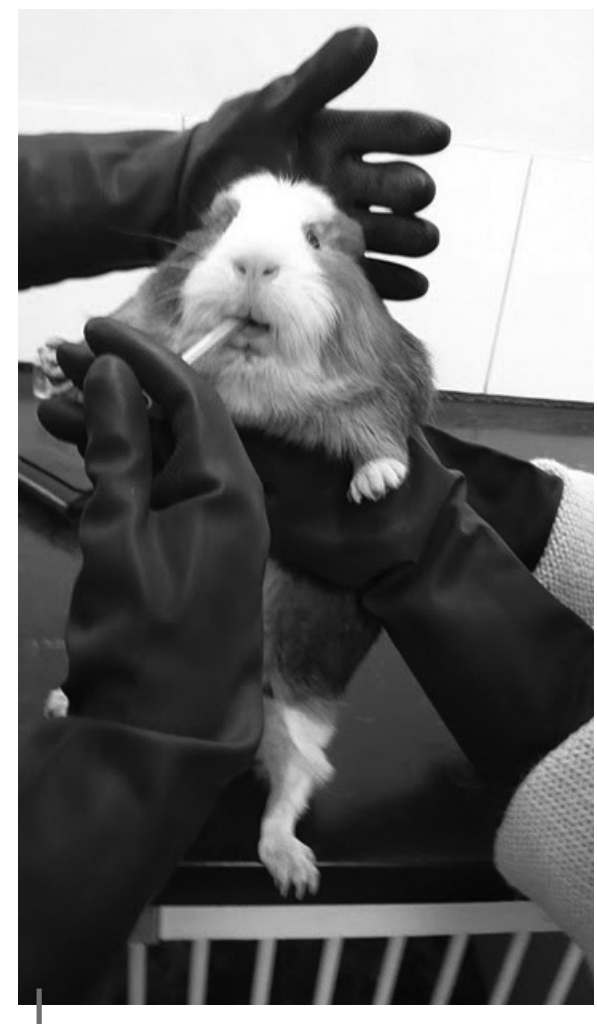

Figura 2 - Applicación diaria de altrenogest por via oral

Foto: Anne Grégoire 
lisis del cuerpo lúteo del ovario, la concentración de progesterona en la sangre disminuye provocando así la ovulación y un nuevo ciclo puede empezar. Para que el tratamiento hormonal tenga el mismo efecto que la secreción natural de hormonas, el animal tratado debe encontrarse en fase lútea y tener un cuerpo lúteo activo. Con el fin de sincronizar un grupo de animales que se encuentran en diferentes fases del ciclo, se decidió aplicar dos inyecciones intra-muscular de luprostiol (análogo sintético de prostaglandinas) con un intervalo de 10 días. En la primera inyección, los animales que se encuentran en fase lútea empiezan un nuevo ciclo y están de nuevo en fase lútea 10 días después, cuando se realiza la segunda inyección. Por otra parte, consideramos que los animales que no se encuentran en fase lútea en el momento de la primera inyección tienen que estar en fase lútea 10 días después, cuando se realiza la segunda inyección, tomando en cuenta que la fase lútea dura 12-13 días de los 16 días del ciclo. Los primero intentos realizados con nulíparas de 6 meses han mostrado que todas las hembras entraron en celos 4-5 días luego de la segunda inyección de luprostiol. Este protocolo alivia mucho el estrés en los animales (dos manipulaciones en total, contra 20 manipulaciones por el tratamiento con progesterona vía oral) y simplifica el trabajo. Los primeros resultados son satisfactorios; sin embargo la aparición de celos en los animales se escalona en 2 a 3 días. Sin embargo, se desea desarrollar un protocolo que permita agrupar mejor los celos, por lo cual se utilizará un nuevo protocolo que combina el uso de progesterona y prostaglandinas.

Nuestros primeros trabajos sobre la sincronización de celos en cuyes nos permiten desarrollar técnicas eficaces y realizables en condiciones de granja. Le segunda etapa de nuestro proyecto es aumentar el número de embriones por hembra, desarrollando un tratamiento de superovulación. Nuestros primeros intentos de sincronización y superovulación con HmG (Human menauposal Gonadotrophin) nos hacen pensar que los embriones transitan más rápidamente en los oviductos de los animales tratados. Nuevos intentos deben permitirnos determinar la velocidad de tránsito de los embriones en los animales sincronizados y superovulados con el fin de colectarlos en el estado mórula compactada (32-64 células) a la altura de la unión entre el oviducto y el útero. La última etapa consistirá este año en definir un protocolo de congelación óptimo para los embriones de Cavia porcellus. Nuestro objetivo es obtener, en el mundo, los primeros cuyes resultantes de una transferencia de embriones congelados.

Es primordial que el Perú controle el manejo de los recursos zoogenéticos de los animales domésticos endémicos del país, como el cuy y la alpaca. La creación de un criobanco nacional de recursos genéticos endémicos permitirá prevenirse tantos de problemas sanitarios como de pérdidas genéticas inestimables.

\section{Referencia citada}

UEDA, H., KOSAKA, T. \& TAKAHASHI, K.W., 1988 - Effects of long-term progesterone treatment on synchronized ovulation in guinea pigs. Zoological Science, $\mathbf{n .}^{\circ}$ 5: 139143. 